Manuscript submitted for publication in Ecological Indicators

\title{
An evaluation of spatial value transfer methods for identifying cultural ecosystem services
}

\author{
[Word count: Approximately xxxx] \\ Greg Brown* \\ School of Geography, Planning and Environmental Management \\ The University of Queensland \\ Brisbane, QLD 4072 \\ greg.brown@uq.edu.au Ph: 0733656654 \\ David Pullar \\ School of Geography, Planning and Environmental Management \\ The University of Queensland \\ Brisbane, QLD 4072 \\ d.pullar@uq.edu.au \\ Vera Helene Hausner \\ Department of Arctic and Marine Biology, Arctic University of Norway, Tromsø, Norway \\ vera.hausner@uit.no
}

*Corresponding author 


\title{
An evaluation of spatial value transfer methods for cultural ecosystem services
}

\begin{abstract}
A significant barrier the assessment of ecosystem services is a lack of primary data, especially for cultural ecosystem services. Spatial value transfer, also known as benefits transfer, is a method used in the absence of primary data to identify the probable locations of ecosystem services based on empirical spatial associations found in other geographic locations. To date, there has been no systematic empirical evaluation of spatial value transfer methods for cultural ecosystem services identified through participatory mapping. This research paper addresses this knowledge gap by examining key variables that can influence value transfer results for cultural ecosystem services: (1) the geographic setting for value transfer, (2) the type of ecosystem services being value-transferred, and (3) the land cover data selected for the value-transfer process. Empirical spatial data collected using public participation GIS (PPGIS) processes in two different regions in Norway were used to evaluate spatial value transfer outcomes (similarity in maps) where the actual mapped distribution of cultural ecosystem values were compared to maps generated using value transfer coefficients. We evaluated spatial value transfer for six cultural ecosystem values using two different land cover classification systems Global Cover (300m resolution) and Corine (100m resolution). Spatial value transfer maps based on the distribution of mapped ecosystem values produced strongly correlated results to primary data in both regions. Given these results, we identify the conditions where it is appropriate to use spatial value transfer for mapping cultural ecosystem services in the absence of primary data.
\end{abstract}

Keywords: ecosystem services, land cover, social values, PPGIS, value transfer

\section{Highlights}

- Identifies spatial associations between cultural ecosystem services (CES) and land cover

- Examines key variables that can influence spatial value transfer outcomes for CES

- Compares spatial value transfer maps generated from primary data in two different regions

- Value transfer maps strongly correlated with maps generated from primary data

- Describes conditions for using spatial value transfer of CES 


\subsection{Introduction}

The Millennium Ecosystem Assessment (2005) established the importance of ecosystem services to human well-being. A logical consequence has been increased effort to identify and map the distribution of ecosystem services globally, but ecosystem services are resource-intensive to identify, inventory, and map. In the absence of primary data in most places, a common method has been the use of proxies based on "benefits transfer" Plummer (2009), also known as "spatial value transfer" (Troy and Wilson, 2006). These methods involve estimating ecosystem benefits from a small region and applying them over a larger area, or stated more generally, the transfer of primary data to areas where no data exist. A common approach is to estimate ecosystem services from land cover data and then apply economic valuation as transfer coefficients (see e.g., Sutton and Costanza, 2002; Troy and Wilson, 2006; Turner et al. 2007; Petrosillo et al, 2009).

Cultural ecosystem services (CES) are a subset of ecosystem services that provide nonmaterial benefits such as spiritual enrichment, cognitive development, reflection, recreation, and aesthetic experiences (MEA, 2005). Identifying the spatial distribution of CES presents special challenges because they are not adequately defined or integrated within the ecosystem services framework (Chan, Guerry et al., 2012; Daniel et al, 2012), are usually intangible and incommensurate with economic valuation methods (Chan et al., 2012; Hernández-Morcillo, Plieninger, Bieling, 2013), may be "bundled” with other ecosystem services (Raudsepp-Hearne et al., 2010), and involve complex psychological dimensions in the valuation process (Kumar and Kumar, 2008). Due to these methodological challenges, cultural ecosystem services are rarely fully considered in ecosystem services assessments (Plieninger et al., 2013).

Most CES are not directly observable in the physical landscape and require (1) proxy or indicator measures derived from observed or inferred human behavior, or (2) direct human inquiry about the benefits received. Proxies may be used to identify the location of CES, for example, the number of tourist attractions as a proxy for tourism benefits or the number of observations of rare species as a proxy for nature appreciation benefits (Raudsepp-Hearne et al. 2010). However, the validity of proxies, especially for CES, is often questionable. Research to collect primary data on CES has increasingly used participatory mapping methods, variously called public participation GIS (PPGIS), participatory GIS (PGIS), and volunteered geographic information (VGI) (see Brown and Fagerholm, 2015; and Brown and Kyttä, 2014, for a review of applications). The mapping of placebased values using PPGIS/PGIS/VGI methods appears valid for identifying CES under the assumption that the values elicited identify locations that directly or indirectly contribute to human well-being. The terms ecosystem "service" and "value" are often conflated in the literature as the terms are closely related. Ecosystem services are the benefits people obtain from ecosystems while ecosystem values are measures of how important ecosystem services are to people. An assumption of participatory mapping is that when a place is identified as valuable by a participant, it is providing a benefit or service. The mapping of ecosystem values identify relationship values (Brown and Weber, 2012) that bridge held values (what is important to the person mapping) and assigned values (the physical place features that contribute to the value).

Participatory mapping methods are a desirable method for identifying CES given their flexibility and adaptability to a wide range of physical and social settings. Specifically, participatory mapping can be designed to identify a full range of CES from aesthetics to "sense of place”, can use digital or non-digital mapping technologies, can use qualitative or quantitative methods, and can target different sampling groups from randomly selected households, to stakeholder groups, to crowd-sourced volunteers. But this methodological pluralism also means that "best practice has yet to coalesce" in the 
mapping of ecosystem services (Brown and Fagerholm, 2015, p.119) resulting in continuing trials and case studies that map CES. Given the effort required to collect primary CES data, there is benefit if the participatory mapping of CES can be meaningfully spatially transferred to other places where primary data does not exist.

The spatial value transfer of CES involves describing the spatial associations between CES and the physical landscape in one area and then applying these associations to other areas or regions. One of the challenges to spatial value transfer is the heterogeneity in global physical environments and diversity in human cultures. For example, the cultural ecosystem service of recreation may found in a wide range of physical environments, from mountains to lakes to urban parks, while preferences for specific types of recreation activities are typically embedded in cultural norms. Significant spatial associations between CES and land cover have been identified in multiple empirical studies (see e.g., Brown, 2013; Brown et al., 2012; Brown and Brabyn, 2012a; 2012b) but the associations vary by place and cultural setting.

Generalization errors are the major threat to the validity of spatial transfer methods. As described by Plummer (2009), generalization error can be subdivided into three components of uniformity, sampling, and regionalization. Uniformity error occurs when ecosystem values are not constant (uniform) for a particular physical environment such as land cover, sampling error results from too few study areas being used to develop transfer indices or coefficients, and regionalization error occurs when the study area is not representative of the area being transfer mapped. These generalization errors have been assessed for biophysical indicators of ecosystem services and appear applicable to value transfer processes that assess CES.

\subsection{Assessment of value-transfer outcomes}

Eigenbrod et al., (2010a) evaluated value-transfer for three ecosystem services in England using land cover proxies. Of particular relevance to this study was their findings related to the benefitstransfer of recreation value, a cultural ecosystem service. Primary recreation data used in the analysis were visits to rural areas collected from a cross-sectional survey of English residents in 2005. Recreation visits were tallied within 10 x $10 \mathrm{~km}$ grid cells and land cover proxy maps were created by assigning values to 11 land cover classes based on the average number of recreation visits for a given land cover class. The bivariate correlation between the primary recreation data and the land cover proxy was 0.42 and increased to 0.54 when recreation hotspots, as a subset of primary data, were analyzed. When purported causal drivers of recreation-access and population density-were included to augment the land cover proxy layer, the correlation between primary data and the proxy layer showed modest improvement to 0.50 .

In subsequent analysis of generalization errors in the benefits transfer, Eigenbroad et al. (2010b) found that variation in ecosystem services within the land cover classes (uniformity error) resulted in a poor fit to primary data, while sampling effects and area extrapolation also contributed to reductions in fit with primary data. Of the four ecosystem services examined in this latter study, recreation had the greatest uniformity error, but lowest regionalization error. The high degree of uniformity error was not surprising given that recreation value tends to be spatially clustered, even within a given land use cover class. The authors concluded that generalization errors were "sufficiently large to undermine decisions that might be based on such extrapolated maps” (Eigenbrod et al., 2010b, p. 2487).

In another benefit-transfer study, Brown et al., (2015) used participatory mapped data that identified places as important for recreation (primary data) in two separate study regions in Norway. In the analysis, the primary spatial data collected in one region was value-transferred to the second region 
based on the proportion of recreation values found in each land cover class. The value-transfer map was compared to the map generated from primary recreation data. The correlation coefficient between the primary data map and the value transfer map was 0.98 indicating a good fit across regions.

\subsection{Research aims and objectives}

The purpose of this study is to examine key variables that can potentially influence valuetransfer outcomes for CES, including the human population and region sampled, the choice of land cover data, and the type and quantity of primary CES data collected. This study expands on Brown et al., (2015) by providing a more comprehensive, empirical evaluation of value-transfer for cultural ecosystem services and includes several novel, operational components: (1) assesses value-transfer outcomes using primary CES data collected in two separate study areas for cross-regional validation of results; (2) examines the potential effects of land cover data on results by using two land cover systems from different sources with different spatial resolution; and (3) assesses value-transfer outcomes for multiple CES to determine their relative performance and suitability for value-transfer methods. Thus, the specific research questions to be examined in this study are as follows:

1) Does the type of cultural ecosystem value being measured affect spatial value-transfer outcomes?

2) Do regional differences in physical landscapes and sampled human populations influence spatial value-transfer outcomes?

3) Given the importance of land cover data as the value-transfer medium, does the choice of land cover data affect transfer outcomes?

4) Under what conditions does spatial value transfer appear appropriate to identify the distribution of cultural ecosystem services?

\subsection{Methods}

\subsection{Study locations}

Two study areas in Norway were selected that provide for contrast in physical landscapes, land tenure systems, and populations (see Figure 1). The southern study area is located in the Sogn region and is characterized by fjords, glaciers, and mountain plateaus. Less than $5 \%$ of the study area is used for cultivation or forestry (Mathiesen et al., 2013). Primary economic activities in the region include livestock grazing, tourism, and hydroelectric power generation, with greater diversity of land use in lowland areas such as cruise tourism, aquaculture, and fruit cultivation. Most villages are small but there are two major hubs, Voss and Sogndal, with 14,006 and 7,623 inhabitants respectively. There are four national parks located in the study region (Breheimen, Jotunheimen, Reinheimen, Jostedalsbreen) situated primarily in the uplands.

The northern study area, Nordland region, is characterized by a narrow coastline with connection to the open sea with small fjords. About half of the study area is owned by the state through the state-owned company Statsskog SF. The alpine areas in the region are important for reindeer husbandry with lichen-rich, good pasture for reindeer. Most of the study area is characterized by rural settlements with residents employed in primary industries. The municipalities of Bodø and Fauske have about 50,000 and 9,000 inhabitants respectively. There are five national parks in the study region: Rago, Sjunkhatten, Junkerdal, Saltfjellet-Svartisen, and Lahko, and five protected landscape areas. 


\section{[Insert Figure 1]}

\subsection{Public Participation GIS (PPGIS) Implementation}

The research team designed, pre-tested, and implemented two internet-based PPGIS websites

for the North and South regions in Norwegian language for data collection. The websites consisted of a Google ${ }^{\circledR}$ maps interface where participants could drag and drop digital markers onto a map of the study area. A panel containing markers with 14 ecosystem values was provided and participants were instructed to drag and drop the markers onto map locations that are important for the values listed (see Table 1). The selection of ecosystem values was based on a typology first developed by Brown and Reed (2000) that was modified and adapted for use in Norway following consultation with protected area managers in the two study areas. The different types of markers and their spatial locations were recorded for each participant in a web server database.

\section{[Insert Table 1]}

Household sampling was used in both the North and South study areas to recruit PPGIS participants. In the South region, about $10 \%$ of the adult population ( $>18$ years) were randomly sampled for a potential 3,104 participants. Sampled individuals were sent a letter of invitation and a reminder two weeks after the initial invitation. Parallel to household recruitment, regional organizations $(n=274)$ were contacted, either by email or Facebook, to inform them about the study and to encourage volunteer participation.

A similar, random household sampling design was used in the North region for a potential 3,054 participants. A total of 216 organizations were also contacted for potential volunteer participation. A total of 440 and 486 individuals from the South and North regions participated in the study between November 2014 to January 1, 2015 for response rates of 14 and 16\% respectively. A detailed profile of study participants is provided in Brown et al., (2015). A total of 19,134 markers were mapped by participants across both study areas.

\subsection{Analyses}

\subsubsection{Selection of ecosystem values for spatial value-transfer}

We selected six of the 14 ecosystem values to evaluate value-transfer outcomes. Three of the ecosystem values would be classified as prima fascia indicators of cultural ecosystem services (recreation, scenery, cultural identity) per the MEA (2005), and three would generally be classified as indicators of provisioning services (hunting/fishing, grazing, gathering). In Norway, however, these three provisioning services also have strong cultural importance given that few people in Norway rely on these services for subsistence. Hunting/fishing and gathering activity appears more important for recreation in Norwegian society while the pasturing of animals provides a supplemental, rather than primary source of income for most Norwegians. We included these multi-function ecosystem values for contrast and comparison with the cultural value results.

\subsubsection{Data preparation and land cover databases}


Two land cover databases were selected for evaluating value transfer methods. The first land cover database, called GlobCover, was developed by the European Space Agency in collaboration with the Université Catholique de Louvain (Bontemps et al., 2011). This is a global land cover with a spatial resolution of $300 \mathrm{~m}$ with 22 land cover classes. The overall accuracy weighted by class area was $67.5 \%$ using 2,190 globally distributed points, including homogeneous and heterogeneous landscapes (Bontemps et al., 2011, p. 47). The second land cover database, called Corine Land Cover (CLC), was developed by the European Union and is maintained by the European Environment Agency. The land cover database has as spatial resolution of $100 \mathrm{~m}$ with 44 classes and a Minimum Mapping Unit (MMU) of 25 hectares. The thematic accuracy of CLC exceeds 85\% (Büttner and Maucha, 2006).

The two land cover layers were clipped to the boundaries of the North and South study areas and spatially intersected with the mapped ecosystem value points. Thus, each mapped ecosystem value was associated a with a specific land cover class. The proportion of ecosystem values that were spatially associated with land cover classes was calculated in each study region.

\subsubsection{Data analysis}

For both GlobCover and Corine land cover data, Chi-square statistics with standardized residuals were calculated to determine whether the number of mapped points for each ecosystem value differed significantly from the expected number of points in each land cover class under the assumption that ecosystem value and land cover class are independent. Standardized residuals greater than +1.96 or less than -1.96 indicate significantly more or fewer mapped points respectively than expected in each class.

In the second analysis, we examined whether the proportion of ecosystem values mapped in each land cover class where significantly different between the North and South regions. Statistical tests for proportional differences between regions were calculated, with z-scores +/-1.96 (two-tailed test, $\alpha=.05$ ) indicating proportionately more or fewer points were mapped in each land cover class.

The percentages of ecosystem values spatially associated with each land cover class were used as value-transfer coefficients. This method assumes that ecosystem values would be similarly distributed across land cover classes where primary data was not collected. The coefficients in the North region were applied to land cover classes in the South, while the coefficients in the South were applied to the North region. This process was completed for both Globcover and Corine land cover data. Thus, for each region and for each ecosystem value, there was a primary or "actual” distribution and a spatial "value-transfer" distribution for each type of land cover data (GlobCover and Corine).

To assess the similarity between the actual (primary) and value-transfer distributions, we generated color-coded maps to provide for qualitative, visual contrast. The maps were generated by applying the proportion of ecosystem values associated with each land cover class in the North study region to the same land cover classes in the South region and vice-versa, for each ecosystem service. The same defined intervals of transfer coefficients (percentages) and color ramps were applied to the two maps (primary and spatial value transfer). To quantify the overall similarity in maps, we calculated Pearson's product moment correlations between spatially-paired cells in the primary and value-transfer maps for each region. This aggregate measure of map similarity accounts for the similarity (or difference) between the primary and transfer values in each land cover class as shown in Tables 3 and 4 (similar primary and transfer values increase the map correlation coefficient) and the proportion of the study region contained in the land cover class (similar primary and transfer values in the largest land cover classes increases the map correlation coefficient). 


\subsection{Results}

\subsection{Relationships between ecosystem values and land cover}

Norway's actual land cover classes comprise a smaller subset of the 22 possible land cover classes identified in the GlobCover system and 44 classes in the Corine system. With GlobCover, 10 of the 22 land classes comprise one percent or more in the North and South study areas compared to 11 of 44 Corine land classes. Land cover in the two study areas is dominated by mixed forests, sparse vegetation, and bare areas with relatively little land in agriculture, grassland, or developed area (see Tables 3 and 4). Within each region, mapped ecosystem values exceeded expected counts based on areal proportions in forest-related land classes including moors and heathland, while most ecosystem values were under-represented in bare, sparsely vegetated, and areas of permanent snow and ice. Scenic, recreation, and hunting/fishing values were disproportionately more abundant in sparsely vegetated areas in the North compared to the South. Cultural values were especially abundant in both study regions in lower elevation areas proximate to human development. The data suggest a type of topographical gradient of values with greater abundance of cultural ecosystem values located in lowlands, especially in the South region.

\section{[Insert Tables 3 and 4]}

There were significant proportional differences between regions in the distribution of ecosystem values by land class, with many differences attributable to differences in the land cover classification system. For example, recreation, scenic, and cultural values were mapped significantly more in the South region in the GlobCover class for closed to open mixed forest (Class 100) while in contrast, these same ecosystem values were mapped disproportionately more in the North region in the Corine land class for broad-leaved forest (Class 311). When general forest cover classes were aggregated in the Globcover and Corine systems, the proportion of the area occupied in each region were similar (within 3-4 percent), but the relative abundance of ecosystem values within the forest cover classes was significantly larger in the Globcover system compared to the Corine system. Another illustrative example is the difference between areas identified as having "sparse" vegetation (Class 150 in GlobCover, Class 333 in Corine). With GlobCover, 43.6\% and 35.6\% of the South and North regions were classified as sparsely vegetated respectively, compared to $31.7 \%$ and $28.6 \%$ with the Corine classification system. These proportional differences in land cover classes between the two classification systems strongly influenced the distribution of mapped ecosystem values falling within specific land cover classes, but the more general patterns of spatial association held, i.e., cultural ecosystem values were disproportionately abundant in vegetated and developed areas, and less abundant in bare, sparse, and glaciated areas. The most striking proportional difference between the North and South regions was for sparse vegetation where North participants mapped significantly more of all ecosystem value types than South participants. These associations between ecosystem values and land cover type determine the spatial value transfer coefficients, which in turn, influence the value transfer outcomes between regions. 


\subsection{Spatial value transfer results with ecosystem value and land cover associations}

The percent of mapped ecosystem values associated with each land cover class were used as spatial value transfer coefficients between the North and South regions. When maps of scenic, recreation, and cultural values in the North region were generated using the proportion of the same ecosystem values from land cover classes in the South region, the resulting maps were quite similar to the actual distribution (see Figure 2). The overall measure of map similarity was large and significant for all cultural ecosystem values using either GlobCover or Corine land cover data. With Globcover, map similarity was $\mathrm{r}=0.98$ for scenic, recreation, and cultural values, and with Corine data, map similarity was slightly less for scenic $(\mathrm{r}=0.95)$, recreation $(\mathrm{r}=0.96)$, and cultural $(\mathrm{r}=0.92)$ values (see Table 4). The spatial value transfer process generated similar results for gathering, grazing, and hunting/fishing values, with somewhat higher correlation coefficients using GlobCover. Of the six ecosystem values, the spatial value transfer of hunting/fishing values to the North produced the least similar maps with correlations or $r=0.91$ and $r=0.73$ for GlobCover and Corine respectively (see Table 4).

When primary data from the North region was used to generate value transfer maps for the South region, the transfer maps were very similar to primary data maps for scenic, recreation, and cultural values (see Figure 3). The correlation coefficients were large and significant for all ecosystem values, and somewhat larger using GlobCover data (see Table 4). The gathering value transfer map was least similar to the primary data map with $r=0.78$ using Corine land cover data.

\subsection{Discussion}

We evaluated spatial value transfer outcomes for six cultural ecosystem values using primary data collected in two regions of Norway and two different land cover classification systems. The spatial value transfer maps were similar to primary data maps, indicating relatively small regionalization and sampling error in the value transfer process. The sample size of one region (transfer from North to South or vice-versa) would suggest a potentially large sampling error, but the more homogeneous the population sampled, the smaller the sample size required. The Norwegian landscape, while topographically diverse, is not diverse in land cover and is dominated by sparse or bare vegetation in the uplands, and mixed forests in the lower elevations. Although the North study region has more coastal area than the South region, the two study areas share common land cover classes in relatively similar proportions. And the two sampled, resident populations that mapped the cultural ecosystem services were similar in socio-demographic profile and used the same participatory mapping protocol to minimize measurement error (Brown et al., 2015). The similarity in physical landscape features and human populations provided a favorable scenario for demonstrating the accuracy of spatial value transfer methods across the two regions. We posit, however, that regionalization error would be larger, for example, if the primary data from the North or South regions were value-transferred to the more urban-influenced and developed areas of southern Norway.

And what of uniformity error, defined is the constancy or uniformity of ecosystem values within a given land cover class? As indicated by the distribution of ecosystem value points plotted in Figures 2 and 3, the mapped locations were not uniformly distributed within land cover classes. In this study, the uniformity error is assumed to be large based on the distribution of point locations. However, uniformity error is expected to be large for cultural ecosystem values given their strong tendency toward spatial clustering (Brown and Donovan, 2014; Brown and Weber, 2012). Cultural identity values, in particular, tend to be associated with specific historical and cultural sites, while non- 
dispersed recreation activities tend to cluster in locations with features such as campgrounds, lakes, and trails. Scenic values also exhibit tendencies toward spatial clustering and would not be expected to be uniform within a given land cover class. Thus, uniformity error is to be expected with cultural ecosystem values but this characteristic does not negate the potential utility of spatial value transfer methods especially if the other sources of generalization error, sampling and regionalization, are relatively small.

\subsection{Conditions for using spatial value transfer for cultural ecosystem services}

We suggest the conditions for conducting spatial value transfer for cultural ecosystem services differ from other biophysical ecosystem services that would be expected to be more tightly coupled with physical land cover characteristics. In their analysis of spatial value transfer error, Eigenbrod et al., (2010b) concluded there is limited range of circumstances where transfer mapping may be suitable: (1) when the heterogeneity of ecosystem services within a land cover type is low, such as in smaller study areas; and (2) where the goal of transfer mapping is to simply to rank the relative importance of a small number of highly distinct land cover types in terms of their importance for one or more ecosystem services. In this study, the heterogeneity of cultural ecosystem services found within the majority land cover classes was relatively high as evidenced by calculated diversity metrics, but this diversity did not negatively influence the spatial value-transfer results. Further, the spatial value transfer was effective across relatively large regions in Norway. In view of these results, we propose a revised set of conditions to reduce generalization error for cultural ecosystem services in spatial value transfer:

1) There should be similarity in the physical land cover classes and areal proportions between the primary data collection region and the spatial value-transfer. Greater landscape homogeneity in the primary and value transfer areas will reduce the potential for sampling and regionalization error. In the absence of similarity, more than one region should be sampled.

2) There should be similarity in the social and cultural values, beliefs, and norms of the human populations living in the primary and value transfer areas. Human populations can be demographically similar in profile but express different cultural ecosystem values. Greater cultural homogeneity in the primary and value transfer area populations will reduce the potential for regionalization error.

3) The sampling methods for mapping cultural ecosystem values should ensure large and unbiased samples, to the fullest extent possible. Participatory mapping processes that rely on volunteer sampling (VGI) or that contain significant participant bias will increase the potential for all error types in the value transfer process.

The suitability of spatial value transfer methods ultimately depends on the intended purpose of the maps. Given the expected uniformity error of cultural values within land cover classes, spatial value transfer methods would be inappropriate as the sole source for identifying place and project-specific impacts, for example, in assessing the social impact of a mining or hydroelectric project. In this situation, primary data should be collected. Spatial value transfer appears more appropriate for identifying broader scale risks to human well-being, for example, from larger-scale land use changes from deforestation, agriculture, or the effects of climate change. In the case of Norway, land use change is the most important driver of biodiversity loss (Norwegian Environment Agency, 2015), http://www.environment.no/topics/biodiversity/?id=16220) and given the high level of cultural 
ecosystem services associated with forest cover described this study, large-scale deforestation may also be considered a critically important driver of cultural ecosystem service loss.

\subsection{Conclusion}




\section{References}

Bontemps, S., Defourny, P., Van Bogaert, E., Arino, O., Kalogirou, V., Ramos Perez, J. 2011. GLOBCOVER 2009-Products description and validation report. Available from < http://due.esrin.esa.int/files/GLOBCOVER2009_Validation_Report_2.2.pdf > Accessed (13 July 2015).

Brown, G., 2013. The relationship between social values for ecosystem services and global land cover: An empirical analysis. Ecosystem Services 5, 58-68.

Brown, G., Montag, J.M., Lyon, K., 2012. Public participation GIS: A method for identifying ecosystem services. Society \& Natural Resources 25, 633-651.

Brown, G., Brabyn, L., 2012a. An analysis of the relationships between multiple values and physical landscapes at a regional scale using public participation GIS and landscape character classification. Landscape and Urban Planning 107, 317-331.

Brown, G., Brabyn, L., 2012b. The extrapolation of social landscape values to a national level in New Zealand using landscape character classification. Applied Geography 35, 84-94.

Brown, G., Donovan, S. 2014. Measuring change in place values for environmental and natural resource planning using Public Participation GIS (PPGIS): Results and challenges for longitudinal research. Society \& Natural Resources 27, 1, 36-54.

Brown, G., Fagerholm, N. 2015. Empirical PPGIS/PGIS mapping of ecosystem services: A review and evaluation. Ecosystem Services 13, 119-133.

Brown, G., Hausner, V., and Lægreid, E. 2015. Physical landscape associations with mapped ecosystem values with implications for spatial value transfer: An empirical study from Norway. Ecosystem Services 15, 19-34.

Brown, G., and Kyttä, M. 2014. Key issues and research priorities for public participation GIS (PPGIS): A synthesis based on empirical research. Applied Geography 46:122-136.

Brown, G., Reed, P. 2000. Validation of a forest values typology for use in national forest planning. Forest Science 46(2), 240-247.

Brown, G., Weber, D. 2012. Using Public Participation GIS (PPGIS) on the Geoweb to monitor tourism development preferences. Journal of Sustainable Tourism 21(2), 192-211.

Büttner, G., \& Maucha, G. (2006). The thematic accuracy of Corine land cover 2000. Assessment using LUCAS (land use/cover area frame statistical survey). European Environment Agency, Copenhagen, Technical Report. 
Chan, K. M., Guerry, A. D., Balvanera, P., Klain, S., Satterfield, T., Basurto, X., ... \& Woodside, U. (2012). Where are cultural and social in ecosystem services? A framework for constructive engagement. BioScience, 62(8), 744-756.

Daniel, T.C., Muhar, A., Arnberger, A., Aznar, O., Boyd, J.W., Chan, K.M.A., Costanza, R., Elmqvist, T., Flint, C.G., Gobster, P.H., Grêt-Regamey, A., Lave, R., Muhar, S., Penker, M., Ribe, R.G., Schauppenlehner, T., Sikor, T., Soloviy, I., Spierenburg, M., Taczanowska, K., Tam, J., von der Dunk, A., 2012. Contributions of cultural services to the ecosystem services agenda. PNAS, 1-8.

Eigenbrod, F., Armsworth, P.R., Anderson, B.J., Heinemeyer, A., Gillings, S., Roy, D.B., Thomas, C.D., Gaston, K.J., 2010a. The impact of proxy-based methods on mapping the distribution of ecosystem services. Journal of Applied Ecology 47, 377-385.

Eigenbrod, F., Armsworth, P. R., Anderson, B. J., Heinemeyer, A., Gillings, S., Roy, D. B., et al. 2010b. Error propagation associated with benefits transfer-based mapping of ecosystem services. Biological Conservation, 143(11), 2487-2493. http://dx.doi.org/10.1016/j.biocon.2010.06.015

Hausner, V., Brown, G., and Lægreid, E. 2015. Effects of land tenure and protected areas on ecosystem services and land use preferences in Norway. Land Use Policy.

Hernández-Morcillo, M., Plieninger, T., Bieling, C. 2013. An empirical review of cultural ecosystem service indicators. Ecological Indicators, 29, 434-444.

Kumar, M., Kumar, P. 2008. Valuation of the ecosystem services: a psycho-cultural perspective. Ecological economics, 64(4), 808-819.

Mathiesen, H., Tenge, I., Lågbu, R., Snellingen Bye, A., 2013. Arealstatistikk: Eiendommer og Utmark. Norsk Institute for Skog og Landskap. Available from: http://www.skogoglandskap.no/filearchive/rapport_21_13_arealstatistikk_eiendommer_og_utmar k.pdf (accessed 13.02.15).

MEA (Millennium Ecosystem Assesment), 2005. Ecosystems and Human Well-being: A Framework for Assessment. Island Press, Washington D.C.

Petrosillo, I., Zaccarelli, N., Semeraro, T., Zurlini, G., 2009. The effectiveness of different conservation policies on the security of natural capital. Landscape and Urban Planning 89, 49-56.

Plieninger, T., Dijks, S., Oteros-Rozas, E., Bieling, C., 2013. Assessing, mapping, and quantifying cultural ecosystem services at community level. Land Use Policy 33, 118-129.

Plummer, M.L. 2009. Assessing benefit transfer for the valuation of ecosystem services. Frontiers in Ecology and the Environment, 7, 38-45 
Raudsepp-Hearne, C., Peterson, G.D., Bennett, E.M., 2010. Ecosystem service bundles for analyzing tradeoffs in diverse landscapes. PNAS 107, 5242-5247.

Troy, A., Wilson, M. A. 2006. Mapping ecosystem services: practical challenges and opportunities in linking GIS and value transfer. Ecological Economics, 60(2), 435-449.

Sherrouse, B.C., Clement, J.M., Semmens, D.J., 2011. A GIS application for assessing, mapping, and quantifying the social values of ecosystem services. Applied Geography 31, 748-760.

Sutton, P.C., Costanza, R., 2002. Global estimates of market and non-market values derived from nighttime satellite imagery, land cover, and ecosystem service valuation. Ecological Economics 41, 509-527.

Turner, W.R., Brandon, K., Brooks, T.M., Costanza, R., da Fonseca, G.A.B., Portela, R., 2007. Global conservation of biodiversity and ecosystem services. Bioscience 57, 868-873. 
Table 1. Ecosystem values typology with operational definitions. Ecosystem values identified with asterisk were used in the valuetransfer assessment.

\begin{tabular}{|c|c|}
\hline Ecosystem Value & Operational definition \\
\hline *Hunting/fishing & Areas are important because of hunting and/or fishing. \\
\hline *Pastures/fodder & Areas are important because they are used for haymaking and pastures for reindeer, sheep, cows \\
\hline *Gathering & Areas are important for berries, mushroom or collecting herbs/plants here. \\
\hline *Recreation & $\begin{array}{l}\text { Areas are important for outdoor recreation activities (e.g., camping, walking, skiing, alpine, snowmobiling, } \\
\text { cycling, horse riding etc.) }\end{array}$ \\
\hline *Scenic areas & Areas are important because they include beautiful nature and/or landscapes. \\
\hline *Culture/identity & $\begin{array}{l}\text { Areas are important because of their historical value, or for passing down the stories, myths, knowledge and } \\
\text { traditions, and/ or to increase understanding of the way of life of our ancestors. }\end{array}$ \\
\hline Water quality & Areas are important because they provide clean water. \\
\hline Biological diversity & Areas are important because they provide a variety of plants, wildlife, and habitat. \\
\hline Income & $\begin{array}{l}\text { Areas are important because they provide tourism opportunities, mining, hydroelectric power or other potential } \\
\text { sources of income. }\end{array}$ \\
\hline Undisturbed nature (naturalness) & Areas are relatively untouched, providing for peace and quiet without too many disturbances. \\
\hline Social & $\begin{array}{l}\text { Areas are important because they provide opportunities for social activities (e.g. associated with fireplaces, } \\
\text { picnic tables, ski -or alpine arrangements, shelters, shared cabins, cabin complexes). }\end{array}$ \\
\hline Spiritual & $\begin{array}{l}\text { Areas are important because they are valuable in their own right or have a deeper meaning; emotionally, } \\
\text { spiritually, or religious. }\end{array}$ \\
\hline Therapeutic/health & $\begin{array}{l}\text { Place are valuable because they make me feel better, either because they provide opportunities for physically } \\
\text { activities important for my health and/or they give me peace, harmony and therapy }\end{array}$ \\
\hline Special places & Please describe why these places are special to you. \\
\hline
\end{tabular}


Table 2. Percentages of mapped ecosystem value points by land cover class (GlobCover) in the South (Sogn) and North (Nordland) study areas. These percentages were used to "value transfer" ecosystem services to the other study area. An asterisk indicates the land cover class was not identified in the region. Bold indicates statistically significant differences in percentages by land cover class in mapped ecosystem services $(\mathrm{p} \leq 0.05)$ between North and South. Green highlighting indicates significantly more ecosystem services than expected in land cover compared to regional land cover proportion while yellow highlighting indicates significantly less ecosystem services than expected in land cover compared to regional land cover proportion.

\begin{tabular}{|c|c|c|c|c|c|c|c|c|c|c|c|c|c|c|}
\hline \multirow[t]{2}{*}{ Global Cover Classification } & \multirow{2}{*}{$\begin{array}{l}\text { Percent } \\
\text { South }\end{array}$} & \multirow{2}{*}{$\begin{array}{l}\text { Percent } \\
\text { North }\end{array}$} & \multicolumn{2}{|c|}{ Recreation } & \multicolumn{2}{|c|}{ Scenic } & \multicolumn{2}{|c|}{ Cultural } & \multicolumn{2}{|c|}{ Hunting/fishing } & \multicolumn{2}{|c|}{ Grazing } & \multicolumn{2}{|c|}{ Gathering } \\
\hline & & & South & North & South & North & South & North & South & North & South & North & South & North \\
\hline 50 Closed broad leaved deciduous & 6.2 & 6.8 & 12.3 & 15.2 & 13.8 & 8.6 & 14.5 & 11.1 & 11.7 & 6.0 & 21.1 & 20.2 & 16.6 & 25.0 \\
\hline $\begin{array}{l}60 \text { Open broadleaved deciduous } \\
\text { forest/woodland }\end{array}$ & 0.0 & 0.0 & 0.0 & 0.0 & 0.0 & 0.0 & 0.0 & 0.0 & 0.0 & 0.0 & 0.0 & 0.0 & 0.0 & 0.0 \\
\hline 70 Closed needle leaved evergreen & 0.1 & 0.4 & 0.2 & 0.4 & 0.0 & 0.7 & 0.0 & 2.1 & 0.0 & 0.6 & 0.0 & 0.0 & 0.0 & 0.4 \\
\hline $\begin{array}{l}\text { evergreen } \\
100 \text { Closed to open mixed broad }\end{array}$ & 10.0 & 6.0 & 14.0 & 10.3 & 11.2 & 13.7 & 11.9 & 12.2 & 11.7 & 15.6 & 16.0 & 7.7 & 17.3 & 6.0 \\
\hline $\begin{array}{l}\text { leaved and needle leaved } \\
110 \text { Closed to open mixed broad }\end{array}$ & 5.7 & 3.8 & 10.8 & 6.3 & 10.0 & 5.8 & 13.2 & 6.9 & 8.5 & 3.9 & 11.1 & 8.9 & 11.5 & 11.7 \\
\hline leaved and needle leaved & 1.4 & 2.1 & 2.0 & 5.6 & 2.4 & 6.8 & 1.6 & 6.3 & 1.2 & 2.4 & 2.0 & 10.5 & 2.7 & 7.1 \\
\hline Total (Classes 50-110) & 23.4 & 19.1 & 39.3 & 37.8 & 37.4 & 35.6 & 41.2 & 38.6 & 33.1 & 28.5 & 50.2 & 47.3 & 48.1 & 50.2 \\
\hline $\begin{array}{l}120 \text { Mosaic grassland forest shrubland } \\
140 \text { Closed to open herbaceous }\end{array}$ & 1.1 & 1.8 & 2.1 & 5.3 & 2.3 & 3.8 & 1.9 & 4.5 & 1.7 & 1.8 & 3.2 & 8.5 & 2.0 & 6.5 \\
\hline vegetation & 0.0 & 0.0 & 0.0 & 0.0 & 0.0 & 0.0 & 0.0 & 0.0 & 0.0 & 0.0 & 0.0 & 0.0 & 0.0 & 0.0 \\
\hline 150 Sparse vegetation & 43.6 & 35.6 & 36.0 & 43.2 & 38.2 & 47.2 & 34.8 & 40.6 & 37.9 & 45.4 & 31.9 & 30.6 & 35.9 & 35.4 \\
\hline $\begin{array}{l}180 \text { Closed to open vegetation } \\
\text { regularly flooded }\end{array}$ & 2.5 & 2.8 & 4.0 & 4.7 & 2.8 & 3.4 & 2.9 & 3.8 & 1.9 & 2.5 & 4.2 & 5.6 & 4.1 & 4.4 \\
\hline 190 Artificial/ developed areas & $*$ & 0.0 & $*$ & 0.2 & * & $\begin{array}{l}0.4 \\
0.1\end{array}$ & * & $\begin{array}{l}0.0 \\
1.7\end{array}$ & $\stackrel{1.5}{*}$ & 0.1 & * & 0.4 & $\begin{array}{c}4.1 \\
*\end{array}$ & $\begin{array}{l}4.4 \\
0.0\end{array}$ \\
\hline 200 Bare areas & 21.3 & 14.7 & 13.4 & 5.6 & 12.6 & 5.2 & 10.6 & 3.5 & 17.6 & 7.5 & 6.6 & 4.0 & 5.4 & 1.3 \\
\hline 210 Water bodies & 4.3 & 22.6 & 3.4 & 2.5 & 3.3 & 3.7 & 4.8 & 5.9 & 5.5 & 13.7 & 2.0 & 3.2 & 1.0 & 2.1 \\
\hline 220 Permanent snow and ice & 4.0 & 3.4 & 1.7 & 0.8 & 3.3 & 0.8 & 3.5 & 1.4 & 2.3 & 0.6 & 2.0 & 0.4 & 3.4 & 0.2 \\
\hline
\end{tabular}


Table 3. Percentage of mapped ecosystem value points by land cover class (Corine) in the South (Sogn) and North (Nordland) study areas. These proportions were used to for "value transfer" to other study area. An asterisk indicates the land cover class was not identified in the region. Bold indicates statistically significant differences in percentages by land cover class in mapped ecosystem services $(\mathrm{p} \leq 0.05)$ between North and South.

\begin{tabular}{|c|c|c|c|c|c|c|c|c|c|c|c|c|c|c|}
\hline \multirow[t]{2}{*}{ Corine Land Cover Classification } & \multirow{3}{*}{$\begin{array}{c}\begin{array}{c}\text { Percent } \\
\text { South }\end{array} \\
0.1\end{array}$} & \multirow{3}{*}{$\begin{array}{c}\begin{array}{c}\text { Percent } \\
\text { North }\end{array} \\
0.2\end{array}$} & \multirow{2}{*}{\multicolumn{2}{|c|}{$\begin{array}{l}\text { Recreation } \\
\text { South }\end{array}$}} & \multicolumn{2}{|c|}{ Scenic } & \multicolumn{2}{|c|}{ Cultural } & \multirow{2}{*}{\multicolumn{2}{|c|}{$\begin{array}{l}\text { Hunting/fishing } \\
\text { South North }\end{array}$}} & \multicolumn{2}{|c|}{ Grazing } & \multicolumn{2}{|c|}{ Gathering } \\
\hline & & & & & South & North & South & & & & & North & South & North \\
\hline 112 Discontinuous urban fabric & & & 1.0 & 0.6 & 2.3 & 0.8 & 5.2 & 10.4 & 1.5 & 0.1 & 0.7 & 2.0 & 0.3 & 0.2 \\
\hline 121 Industrial or commercial units & 0.0 & 0.0 & 0.2 & 0.0 & 0.5 & 0.0 & 1.0 & 0.3 & 0.4 & 0.0 & 0.0 & 0.0 & 0.3 & 0.0 \\
\hline 123 Port areas & * & 0.0 & * & 0.1 & * & 0.0 & * & 0.3 & * & 0.0 & * & 0.0 & * & 0.0 \\
\hline 124 Airports & 0.0 & 0.0 & 0.2 & 0.0 & 0.0 & 0.0 & 0.3 & 0.0 & 0.1 & 0.0 & 0.0 & 0.0 & 0.0 & 0.0 \\
\hline 141 Green urban areas & 0.0 & 0.0 & 0.4 & 0.1 & 0.2 & 0.1 & 0.3 & 0.3 & 0.1 & 0.0 & 0.2 & 0.0 & 0.0 & 0.0 \\
\hline 142 Sport and leisure facilities & 0.0 & 0.0 & 0.1 & 0.1 & 0.1 & 0.2 & 0.3 & 0.3 & 0.0 & 0.1 & 0.0 & 0.0 & 0.0 & 0.0 \\
\hline 211 Non-irrigated arable land & 0.5 & 0.0 & 0.9 & 0.7 & 0.2 & 0.7 & 1.9 & 1.0 & 1.0 & 0.1 & 1.7 & 2.8 & 0.7 & 0.0 \\
\hline 231 Pastures & 0.0 & 0.0 & 0.0 & 0.1 & 0.0 & 0.1 & 0.3 & 0.0 & 0.0 & 0.0 & 0.0 & 0.0 & 0.0 & 0.0 \\
\hline 242 Complex cultivation patterns & 0.4 & 0.1 & 0.9 & 0.3 & 0.9 & 1.2 & 1.6 & 1.7 & 0.9 & 0.0 & 2.0 & 1.2 & 1.0 & 0.0 \\
\hline $\begin{array}{l}243 \text { Agriculture, w/significant } \\
\text { areas natural vegetation }\end{array}$ & 1.5 & 1.2 & 6.2 & 3.1 & 8.4 & 4.2 & 13.9 & 7.3 & 6.9 & 2.9 & 8.1 & 16.1 & 6.8 & 4.4 \\
\hline 311 Broad-leaved forest & 11.8 & 14.1 & 19.1 & 29.0 & 17.9 & 25.2 & 14.5 & 19.4 & 13.7 & 13.6 & 29.0 & 27.4 & 21.7 & 41.9 \\
\hline 312 Coniferous forest & 5.9 & 1.2 & 9.3 & 4.1 & 6.2 & 3.0 & 8.7 & 1.4 & 6.7 & 1.7 & 8.6 & 2.4 & 18.0 & 7.3 \\
\hline 313 Mixed forest & 1.2 & 0.6 & 1.7 & 1.1 & 1.5 & 1.1 & 1.3 & 1.7 & 1.0 & 0.4 & 2.2 & 1.2 & 1.4 & 0.8 \\
\hline Total (Classes 311-313) & 18.9 & 15.9 & 25.6 & 29.3 & 24.5 & 22.5 & 21.4 & 15.7 & 39.8 & 31 & 41.1 & 50 & 18.9 & 15.9 \\
\hline 322 Moors and heathland & 14.6 & 12.1 & 16.7 & 14.9 & 14.8 & 15.4 & 12.3 & 15.3 & 15.2 & 12.7 & 17.2 & 16.1 & 19.7 & 12.1 \\
\hline 332 Bare rocks & 18.8 & 10.3 & 9.7 & 7.6 & 10.9 & 6.8 & 6.8 & 3.1 & 8.6 & 3.7 & 4.4 & 3.2 & 2.7 & 3.5 \\
\hline 333 Sparsely vegetated areas & 31.7 & 28.6 & 21.4 & 28.1 & 21.1 & 27.9 & 17.1 & 24.0 & 20.4 & 31.9 & 15.7 & 19.4 & 15.9 & 22.3 \\
\hline 335 Glaciers and perpetual snow & 5.4 & 3.2 & 3.9 & 0.6 & 4.8 & 0.5 & 5.8 & 0.3 & 2.5 & 0.2 & 2.5 & 0.0 & 3.4 & 0.0 \\
\hline 412 Peat bogs & 0.9 & 1.2 & 1.4 & 2.3 & 1.1 & 1.8 & 1.3 & 0.3 & 1.2 & 1.7 & 2.5 & 3.2 & 2.4 & 2.5 \\
\hline 423 Intertidal flats & * & 0.1 & * & 0.2 & * & 1.1 & * & 0.7 & * & 0.2 & * & 0.0 & * & 0.2 \\
\hline 511 Water courses & 0.0 & 0.0 & 0.0 & 0.1 & 0.1 & 0.0 & 0.0 & 0.0 & 0.0 & 0.0 & 0.0 & 0.0 & 0.0 & 0.0 \\
\hline 512 Water bodies & 3.6 & 4.9 & 4.9 & 3.6 & 5.0 & 2.3 & 3.5 & 3.5 & 17.9 & 16.1 & 4.2 & 1.6 & 5.4 & 3.5 \\
\hline 990 Unclassified & 3.6 & 21.7 & 2.2 & 3.2 & 3.9 & 7.6 & 3.9 & 8.3 & 1.9 & 14.3 & 1.0 & 3.2 & 0.3 & 1.3 \\
\hline
\end{tabular}


Table 4. Similarity metrics (correlation coefficients) for North and South region maps with spatial value transfer of ecosystem services. Correlations measure similarity between maps generated from primary data in region and the transfer map generated from values in the other region.

\begin{tabular}{lcccc}
\hline \multirow{2}{*}{$\begin{array}{l}\text { Ecosystem value } \\
\text { Global Cover }\end{array}$} & 0.98 & 0.97 & \multicolumn{2}{c}{ North Region (Nordland) } \\
Corine Land Cover & Global Cover & Corine Land Cover \\
\hline Scenic & 0.98 & 0.95 & 0.98 & 0.95 \\
Recreation & 0.99 & 0.94 & 0.98 & 0.96 \\
Cultural & 0.95 & 0.78 & 0.98 & 0.92 \\
Gathering & 0.98 & 0.95 & 0.96 & 0.85 \\
Grazing & 0.94 & 0.89 & 0.98 & 0.96 \\
Hunting/fishing & & & 0.91 & 0.73 \\
\hline
\end{tabular}


Figure 1. Two study areas located in: (a) southern Norway (Sogn), and (b) northern Norway (Nordland). Maps show land tenure and the number of study participants by geographic location.

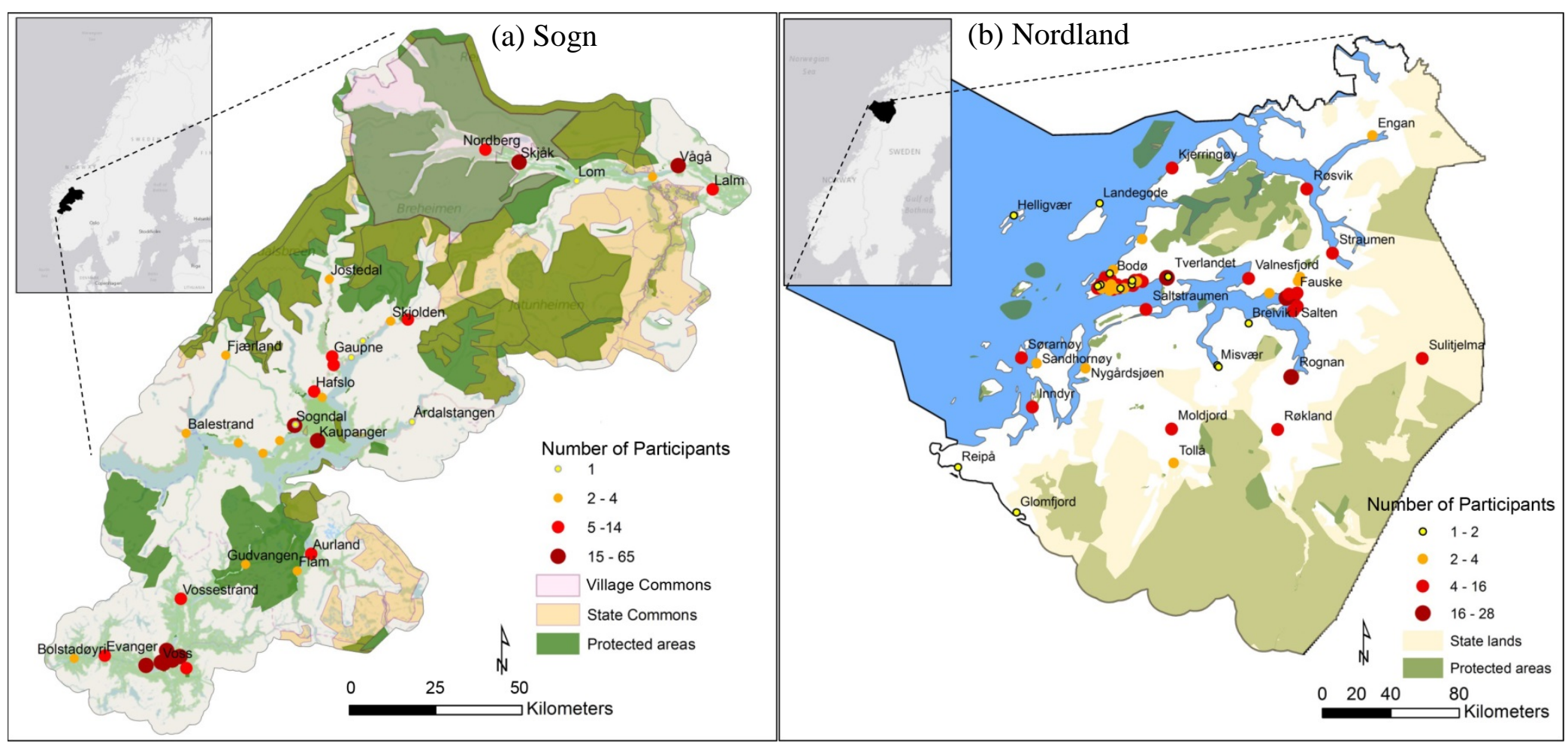


Figure 2. Top panel: maps showing primary data for mapped ecosystem values (points) collected in North region with percent of points by Global Cover classes for (a) scenic (b) recreation, and (c) cultural values. Bottom panel: maps generated using spatial value transfer coefficients generated from primary data collected in the South region. Map similarity calculated using product-moment correlations between actual and value-transfer spatially-paired cells.

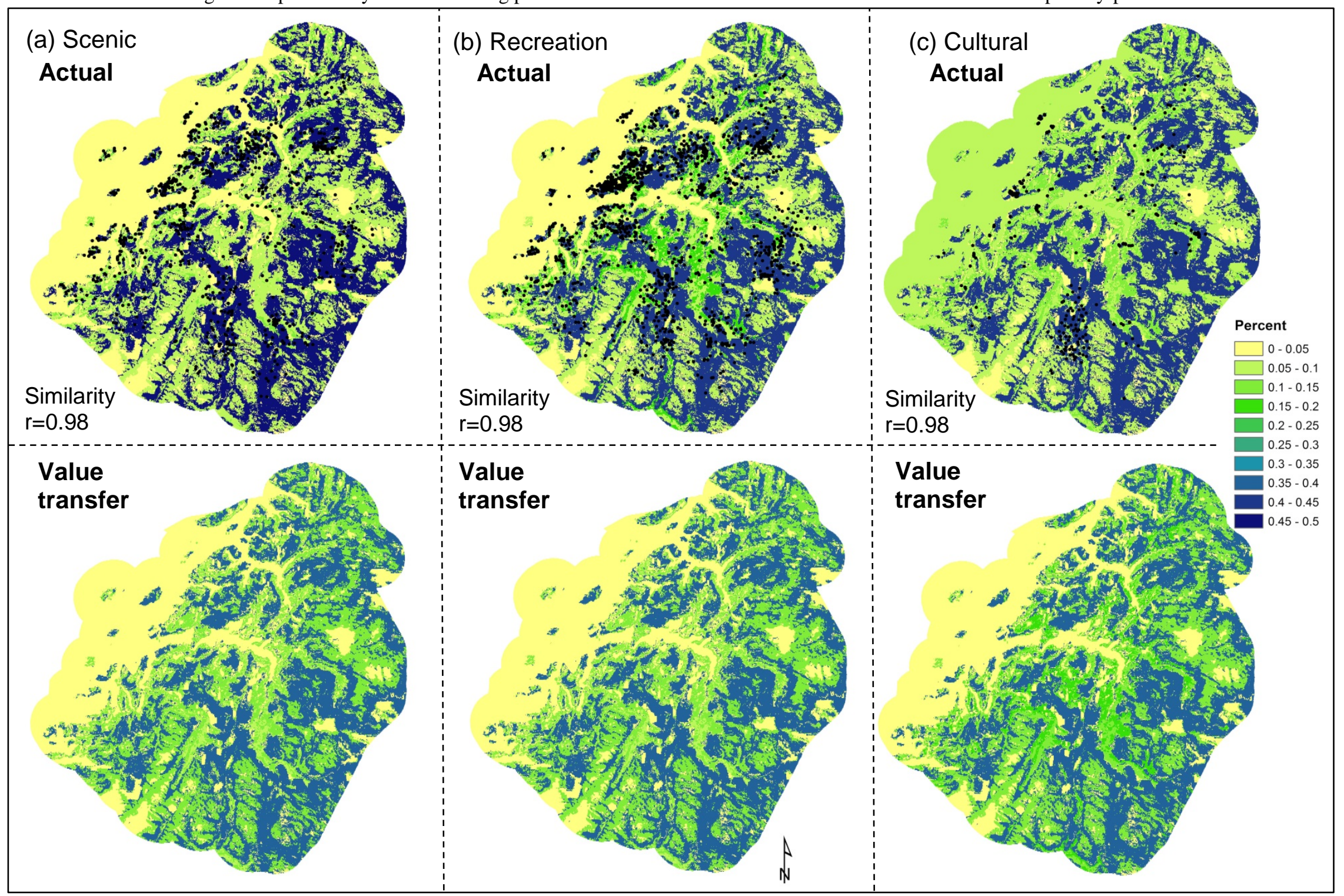


Figure 3. Top panel: maps showing primary data for mapped ecosystem values (points) collected in South region with percent of points by Corine classes for (a) scenic (b) recreation, and (c) cultural values. Bottom panel: maps generated using spatial value transfer coefficients generated from primary data collected in the North region. Map similarity calculated using product-moment correlations between actual and value-transfer spatially-paired cells.

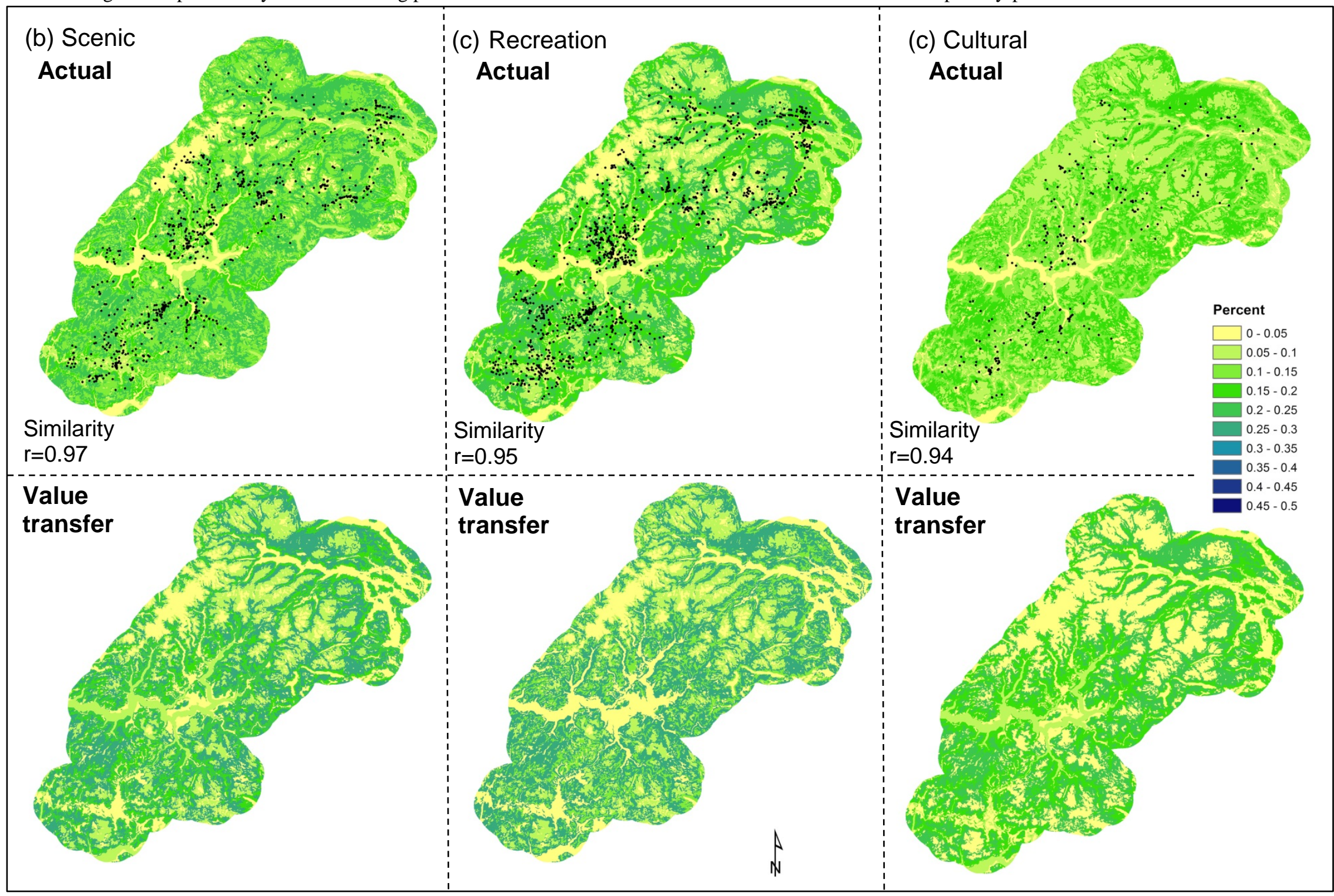


Page 22 of 22 